\title{
GEOLOGIA DO QUATERNÁRIO COSTEIRO DO ESTADO DE PERNAMBUCO
}

\section{JOSÉ MARIA LANDIM DOMINGUEZ*, ABÍLIO CARLOS DA SILVA PINTO BITTENCOURT*, ZELINDA MARGARIDA DE ANDRADE NERY LEÃO* e ANTÔNIO EXPEDITO GOMES DE AZEVEDO**}

\begin{abstract}
QUATERNARY COASTAL GEOLOGY OF THE STATE OF PERNAMBUCO, BRAZIL. This paper presents a geological map of Quaternary deposits occuring along the coast of the State of Pernambuco. These deposits comprise: 1 . two sets of beach-ridge terraces of Pleistocene (120,000 years B.P.) and Holocene (5,000 years B.P.) age; 2. paleolagoonal deposits $(5,140-6,030$ years B.P.); 3. sandstone and coralgal reefs with ages spanning from 1,830 to 5,170 years B.P.; and 4. alluvial, freshwater swamp, and mangrove swamp deposits of Holocene age. Integration of this mapping with the known sea-level history for the east coast of Brazil suggests that previously published evolutionary schemes proposed for the coast of the states of Alagoas, Sergipe, Bahia, Rio de Janeiro, and São Paulo are also valid for the coast of the State of Pernambuco. This evolutionary history shows that sedimentation along the coastal zone was controlled fundamentally by the Quaternary sea-level changes. Eighteen new radiocarbon dates of paleolagoonal deposits, sandstone reefs, coral, coralline algae, and vermetid gastropod incrustations are also reported herein.
\end{abstract}

Keywords: Sea level changes, coastal sedimentation, Quaternary.

\begin{abstract}
RESUMO Este trabalho apresenta um mapa geológico dos depósitos quaternários que ocorrem ao longo da costa do Estado de Pernambuco. Esses depósitos compreendem: 1. dois conjuntos de terracos marinhos de idades pleistocênica (120.000 anos A.P.) e holocênica (5.000 anos A.P.); 2. depósitos paleolagunares (5.140-6.030 anos A.P.); 3. bancos de arenito e recifes de corais e de algas coralinas com idades entre 1.830 e 5.170 anos A.P.; e 4. depósitos aluviais, de pântanos e de mangues, todos de idade holocênica. A integração desse mapeamento com a já bem conhecida história das variações do nível relativo do mar na costa leste brasileira sugere que o modelo de evolução, já previamente publicado, para as regiões costeiras dos Estados de Alagoas, Sergipe, Bahia, Rio de Janeiro e São Paulo, é também válido para a costa do Estado de Pernambuco. Essa historia evolutiva mostra que a sedimentação ao longo da região costeira foi controlada fundamentalmente pelas variações ocorridas no nível do mar durante o Quaternário. Dezoito novas datações pelo método do carbono 14, realizadas em depósitos paleolagunares, bancos de arenito, corais, algas coralinas e incrustações de vermetfdeos, são também reportadas no presente trabalho.
\end{abstract}

Palavras-chaves: Variações do nível do mar, sedimentação costeira, Quaternário.

INTRODUÇÃO Os trabalhos existentes sobre a geologia dos sedimentos quaternários ocorrentes na faixa costeira do Estado de Pernambuco são esparsos e, no mais das vezes, relacionados aos recifes de corais e bancos de arenitos que ocorrem ao longo de quase toda sua extensão. Todavia, nesses trabalhos são apontadas diversas evidências de níveis marinhos elevados durante o Quaternário. Assim, a partir do estudo de suas estruturas sedimentares, de sua petrografia e de seu posicionamento em relação ao nível médio atual do mar, Otmann (1960), Mabesoone (1964) e Bigarella (1975), entre outros, apontam os bancos de arenito como testemunhos de um nível do mar mais alto que o atual durante o Quaternário. Rebouças (1965/1966) e Laborei (1969a) mencionam como evidências de níveis de mar holocênicos mais elevados superfícies de abrasão em recifes de corais. Branner (1902), Moraes (1928) e Kegel (1955), a partir da observação de perfurações de ouriços-do-mar situadas acima da zona ecológica atual desses organismos, também sugerem níveis de mar quaternários mais elevados. Foram identificados ainda terraços marinhos elevados ao nível de 2 a $3 \mathrm{~m}$ de altura por Mabesoone $(1966,1978)$ e por Carvalho \& Coutinho (1979), tendo os dois últimos também mencionado a existência de um segundo nível entre 7 e $8 \mathrm{~m}$. Datações radiométricas efetuadas por Van Andei \& Laborei (1964) e Delibrias \& Laborei (1971) em amostras de vermetídeos, corais e bancos de arenito confirmam também a existência de níveis marinhos holocênicos elevados na costa de Pernambuco. Por fim, como principal objetivo do presente trabalho, foi feito o mapeamento da litoestratigrafia do Quaternário costeiro do Estado de Pernambuco que, até então, pelo conhecimento dos autores, restringia-se apenas a uma pequena área de $180 \mathrm{~km}^{2}$, ao sul da cidade do Recife, na região da Lagoa Olhos-d'água (Fig. 3), em trabalho realizado por Carvalho \& Coutinho (1979).

Durante o presente trabalho foram ainda realizadas no Laboratório de Física Nuclear Aplicada do Instituto de Física da UFBa 18 dataç̃es pelo método do carbono - 14 em amostras de diferentes testemunhos de níveis marinhos elevados durante o Quaternário, tais como vermetídeos, corais, algas calcárias e conchas coletadas em banco de arenito e sedimentos lagunares. Como resultado desse trabalho, foi possível concluir que o modelo evolutivo da sedimentação quaternária definido para as regiões costeiras de São Paulo e Rio de Janeiro (Suguio \& Martin 1978), Bahia (Martin et al. 1980), Sergipe (Bittencourt et al. 1983a e b) e Alagoas (Barbosa et al. 1986 $\mathrm{a}$ e b) pode ser perfeitamente aplicado à costa do Estado de Pernambuco. Assim é que foram identificados em Pernambuco testemunhos de dois níveis marinhos elevados. O primeiro, holocênico, está relacionado à transgressão denominada por Bittencourt et al. (1979) de Última Transgressão, que alcançou um máximo em torno de $5 \mathrm{~m}$ acima do nível médio atual do mar por volta de 5.100 anos A.P. (Martin et al. 1979). O segundo, pleistocênico, está associado à transgressão denominada por Bittencourt et al. (1979) de Penúltima Transgressão, cujo máximo, de 8 a $10 \mathrm{~m}$ acima do nível médio do mar, foi alcançado há cerca de 120.000 anos A.P. (Martin et al. 1982).

Â presente nota, portanto, deixará de discutir as diferentes etapas da evolução quaternária costeira do Estado de Pernambuco, já que tal modelo evolutivo está compreensivelmente

\footnotetext{
* Programa de Pesquisa e Pós-Graduação em Geofísica, Instituto de Geociências da UFBa, Rua Caetano Moura, 123, Campus Universitário, Federacão, CEP 40210, Salvador, Bahia, Brasil

** Programa de Pesquisa e Pós-Graduação em Geofísica, Instituto de Física da UFBa, Rua Caetano Moura, 123, Campus Universitário, Federação, CEP 40210, Salvador, Bahia, Brasil
} 
descrito nos trabalhos semelhantes realizados em São Paulo, Rio de Janeiro, Bahia, Sergipe e Alagoas, não só nas referências acima mencionadas como na síntese preparada por Suguio et al. (1985). A importância da contribuição do presente trabalho reside no fato de ser apresentado pela primeira vez um mapa geológico dos depósitos quaternários, que cobre toda a costa do Estado de Pernambuco, bem como uma série de novas datações radiométricas que comprovam a existência de níveis marinhos elevados durante o Quaternário nessa região.

GEOLOGIA REGIONAL Uma breve descrição das litologias pré-quaternárias que delimitam os contornos da planície costeira do Estado de Pernambuco é apresentada a seguir, a partir de Caúla (1974). Tal descrição se faz necessária porque fornece uma idéia dos diferentes tipos de rochas atacados pelo mar em cada uma de suas elevações durante o Quaternário e que, no fim, devem representar as principais fontes dos sedimentos quaternários aí que ocorrem, pois os rios que déságuam na costa e que podem ter trazido materiais provenientes de outras rochas localizadas mais para o interior do continente são dê pequeno porte. Desse modo, pela figura 1, pode-se observar que o embasamento cristalino, constituído por granitos e migmatitos do Pré-Cambriano Indiviso, ocupa praticamente toda a região a sul da cidade do Recife. Pela mesma figura constata-se que as seqüências sedimentares são representadas pelas formações Cabo, Beberibe e Gramane, de idades cretáceas, e pelo Grupo Barreiras, terciário. As três

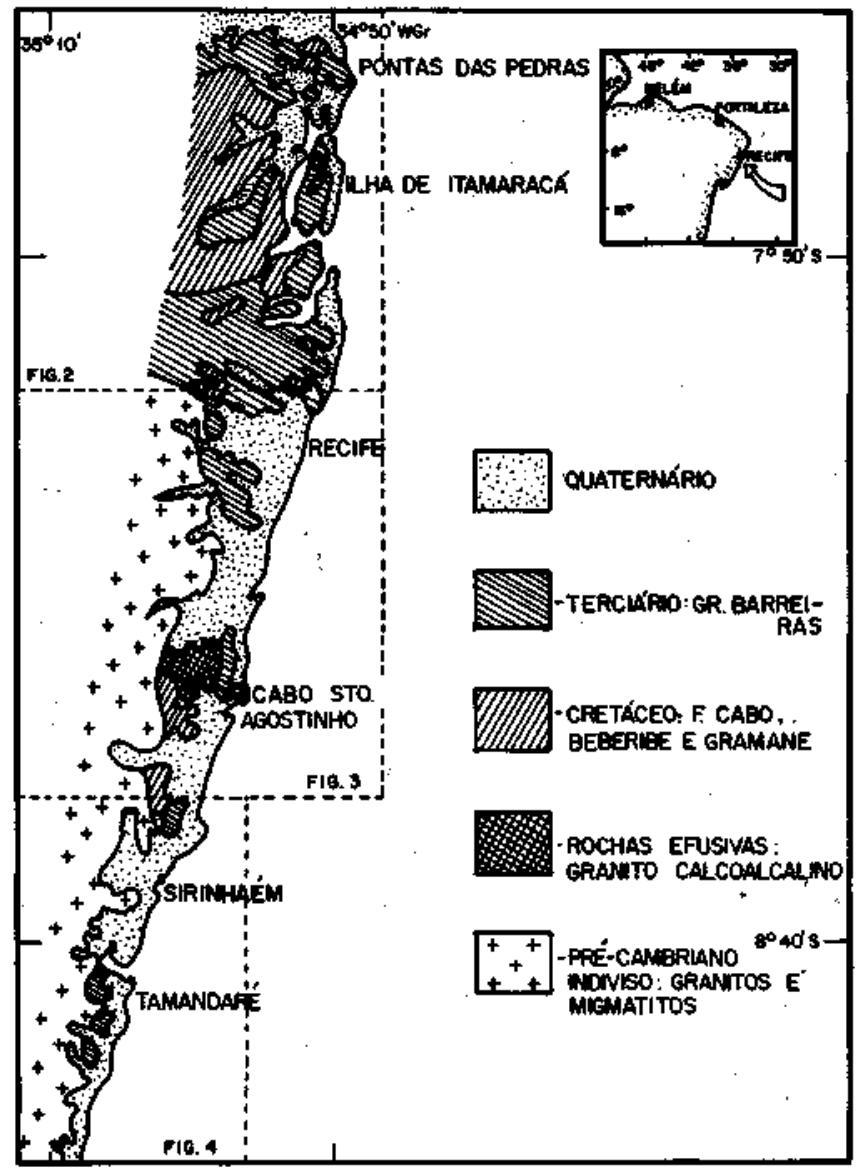

Figura 1 - Mapa geológico geral da costa do Estado de Pernambuco e das áreas adjacentes, mostrando a articulação das figuras 2, 3 e 4 mencionadas no texto (Modificado de Caúla, 1974)

Figure 1 - Simplified geologic map of the coastal zone of the State of Pernambuco and adjacent areas (modified from Caúla, 1974). Location of figures 2,3 and 4 is also shown primeiras formações, que por uma dificuldade de escala aparecem na figura 1 mapeadas conjuntamente, ocorrem em maiores extensões a norte do Recife, aflorando apenas em duas pequenas áreas isoladas a sul. Essas formações são constituídas dos seguintes tipos litológicos: Formação Cabo - conglomerados, arenitos e siltitos argilosos; Formação Beberibe arenitos argilosos: e Formação Gramane - calcarenitos, margas e calcários. À semelhança das seqüências sedimentares cretáceas, os depósitos do Grupo Barreiras, areno-argilosos, ocorrem em maior extensão a norte do Recife, restringindo-se a pequenos e esparsos afloramentos a sul. Por fim, há que se mencionar a ocorrência, nas imediações do Cabo de Santo Agostinho (Fig. 1), de rochas efusivas cretáceas, dos tipos riólito e basalto, associadas ao granito calco-alcalino de Santo Agostinho, de idade também cretácea.

DEPÓSITOS QUATERNÁRIOS COSTEIROS Os depósitos quaternários mapeados ao longo da costa do Estado de Pernambuco vêm descritos a seguir (Figs. 2,3 e 4).

Terraços marinhos Ao longo da costa de Pernambuco aparecem bem marcados dois conjuntos de terraços arenosos com características tipicamente marinhas. Os terraços mais altos, com altitudes de 7 a $11 \mathrm{~m}$ acima da preamar atual, apresentam em alguns afloramentos vestígios de antigas cristas de cordões litorâneos, como na região entre a Lagoa Olhos-d'Agua e Boa Viagem (Fig. 3), onde aí também os descrevem Carvalho \& Coutinho (1979). No mais das vezes, as ocorrências desses terraços se apresentam na forma de pequenas manchas, descontinuamente dispostas ao longo da costa (Figs. 2, 3 e 4). O segundo conjunto de terraços, com altitudes variando de 1 a $5 \mathrm{~m}$ acima da preamar atual, e sempre mais externos em relação aos terraços mais altos, dispõe-se quase que continuamente ao longo da costa, formando faixas alongadas de larguras variáveis, quase sempre apresentando cristas de cordões litorâneos na superfície (Figs. 2, 3 e 4). Esses cordões, diferentemente daqueles existentes na superfície dos terraços mais altos, são bem delineados e próximos entre si. Bons exemplos dessas feições geomórficas podem ser vistos nas regiões entre as praias de Maria Farinha e Rio Doce (Fig. 2), entre as praias de Guadalupe e Várzea do Una (Fig. 4) e defronte à Lagoa Olhos-d'agua (Fig. 3), local onde Carvalho \& Coutinho (1979) também originalmente os descreveram.

Quanto à idade desses dois níveis de terraços, Carvalho \& Coutinho (1979) os associam à transgressão Flandriana, atribuindo-lhes, portanto, uma idade holocênica. Embora não se disponham de datações desses terraços para a região costeira do Estado de Pernambuco, podem ser feitas as seguintes considerações no sentido de posicioná-los no tempo. Esses dois níveis de terraços apresentam características geomórfico-sedimentológicas idênticas às observadas por Barbosa et al. (1986a, b) nos dois conjuntos de terraços marinhos mapeados na costa do Estado de Alagoas, contígua à de Pernambuco, características essas que se mantêm sempre as mesmas ao longo das regiões costeiras de Sergipe (Bittencourt et al. 1983a, b), Bahia (Martin et al. 1980), Rio de Janeiro e São Paulo (Suguio \& Martin 1978). No caso dos terraços mais baixos, essa similaridade é ainda mais evidente pelo fato de os mesmos poderem ser seguidos quase que continuamente de cada uma dessas regiões costeiras para a outra, praticamente só interrompidos pelos cursos de água e promontories rochosos. Esses fatos, portanto, sugerem estar os dois níveis de terraços marinhos mapeados na costa do Estado de Pernambuco relacionados geneticamente a terraços semelhantes identificados nas regiões costeiras acima mencionadas. Em relação à idade dos terraços mais altos, até então só se conseguiram indicações na costa do Estado da Bahia, onde Martin et al. (1982) mencionam uma idade pleistocênica, em torno de 120.000 anos A.P., baseados em datações pelo método do Io/U. Essa 


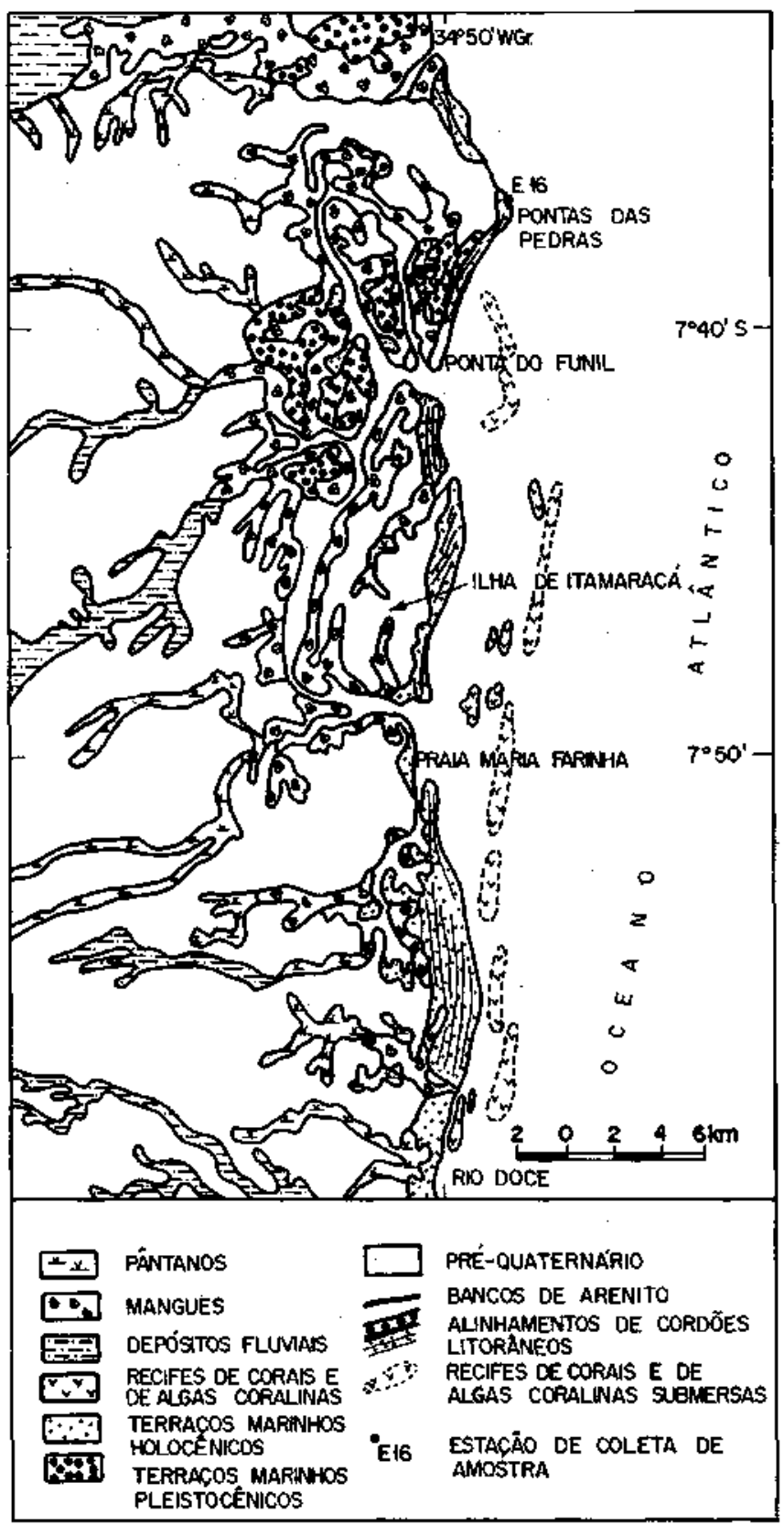

Figura 2 - Mapa geológico do Quaternário costeiro do Estado de Pernambuco: trecho Pontas das Pedras-Rio Doce

Figure 2 - Geologic map of the Quaternary coastal deposits of the State of Pernambuco; sector Pontas das Pedras-Rio Doce

idade coincide com o máximo de uma transgressão marinha, de caráter eustático, cuja altura alcançada acima do nível atual do mar é compatível com a altura dos terraços mais altos mapeados nas regiões costeiras de Pernambuco, Alagoas, Sergipe, Bahia, Rio de Janeiro e São Paulo. Vale ressaltar que evidências de níveis marinhos nessa altura associados à transgressão de 120.000 anos A.P. já foram identificados em diversas outras partes do mundo (Bloom et al. 1974, Chapei \& Veeh 1978). Quanto aos terraços mais baixos existem diversas datações na costa brasileira que os posicionam como de idade holocênica, como sugerem Carvalho \& Coutinho (1979). Assim, por exemplo, na costa do Estado de Alagoas, Barbosa et al. $(1986 \mathrm{a}, \mathrm{b})$ dataram quatro amostras de níveis conchíferos inclusos nesses terraços que apresentaram idades entre 2.570 \pm 170 (Bah 1168) e $3.690 \pm 180$ anos A.P. (Bah 1145).

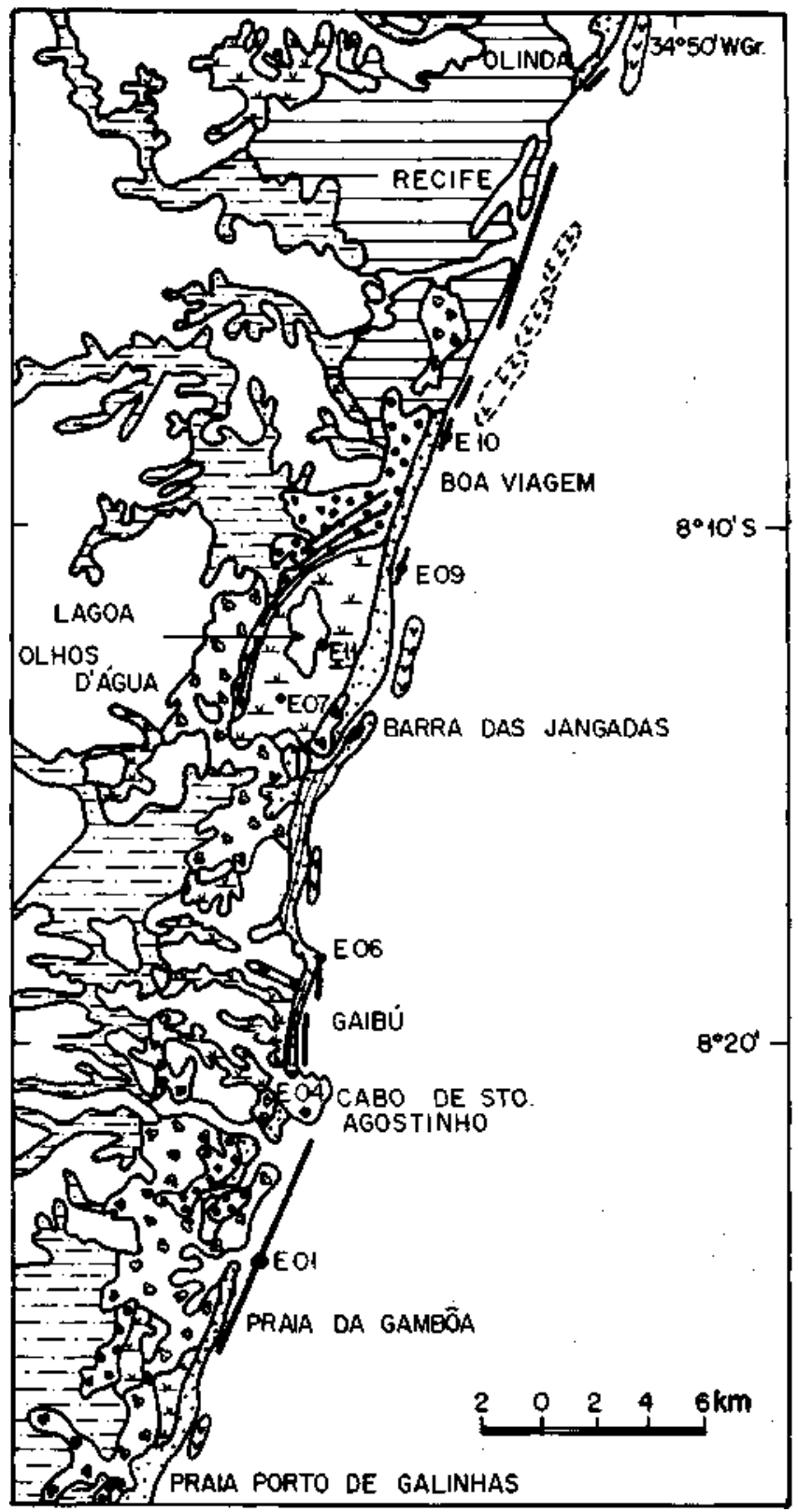

Figura 3 - Mapa geológico do Quaternário costeiro do Estado de Pernambuco: trecho Olinda-Praia Porto de Galinhas (Simbologia da Fig. 2)

Figure 3 - Geologic map of the Quaternary coastal deposits of the State of Pernambuco: sector Olinda-Praia Porto de Galinhas beach (See Fig. 2 for legend)

Depósitos fluviais Esses depósitos, constituídos por areias finas a grossas síltico-argilosas, ocupam as partes baixas das porções proximais de vales de rios e riachos (Figs. 2, 3 e 4).

Como esses vales foram invadidos durante o máximo da Última Transgressão, é muito provável que esses depósitos fluviais estejam capeando sedimentos de origem lagunar/estuarina, a exemplo do reportado por Barbosa et al. (1986a) para a costa do Estado de Alagoas.

Depósitos de pântanos Esses depósitos, constituídos por argilas muito orgânicas, ocorrem principalmente nas zonas baixas separando terraços marinhos holocênicos e pleistocênicos (Fig. 3) e nos vales dos rios e riachos que não foram 
preenchidos por sedimentos fluviais (Fig. 2 e 3).

Observa-se em escavações rasas que os depósitos de pântanos representam apenas uma fina camada recobrindo sedimentos síltico-argilosos ricos em matéria orgânica e contendo localmente pedaços de madeira, conchas marinhas e de água salobra, algumas em posição de vida, o que permite atribuir a esses sedimentos uma origem lagunar-estuarina. Essas lagunas/estuários, a exemplo do que ocorreu em outros trechos da costa leste do Brasil, estão associadas ao afogamento da região costeira durante a Última Transgressão. Com a descida subseqüente do nível do mar, essas lagunas ficaram emersas sendo substituídas por pântanos de água doce. $\mathrm{Na}$ região da Lagoa Olhos-d'Agua (Fig. 3), conchas em posição de vida coletadas nos sedimentos dessa antiga laguna apresentaram idades relacionadas à Ultima Transgressão com valores de $5.140 \pm 230$ (Bah 1215) e $5.830 \pm 230$ anos A.P. (Bah 1216) (Tab. 1).

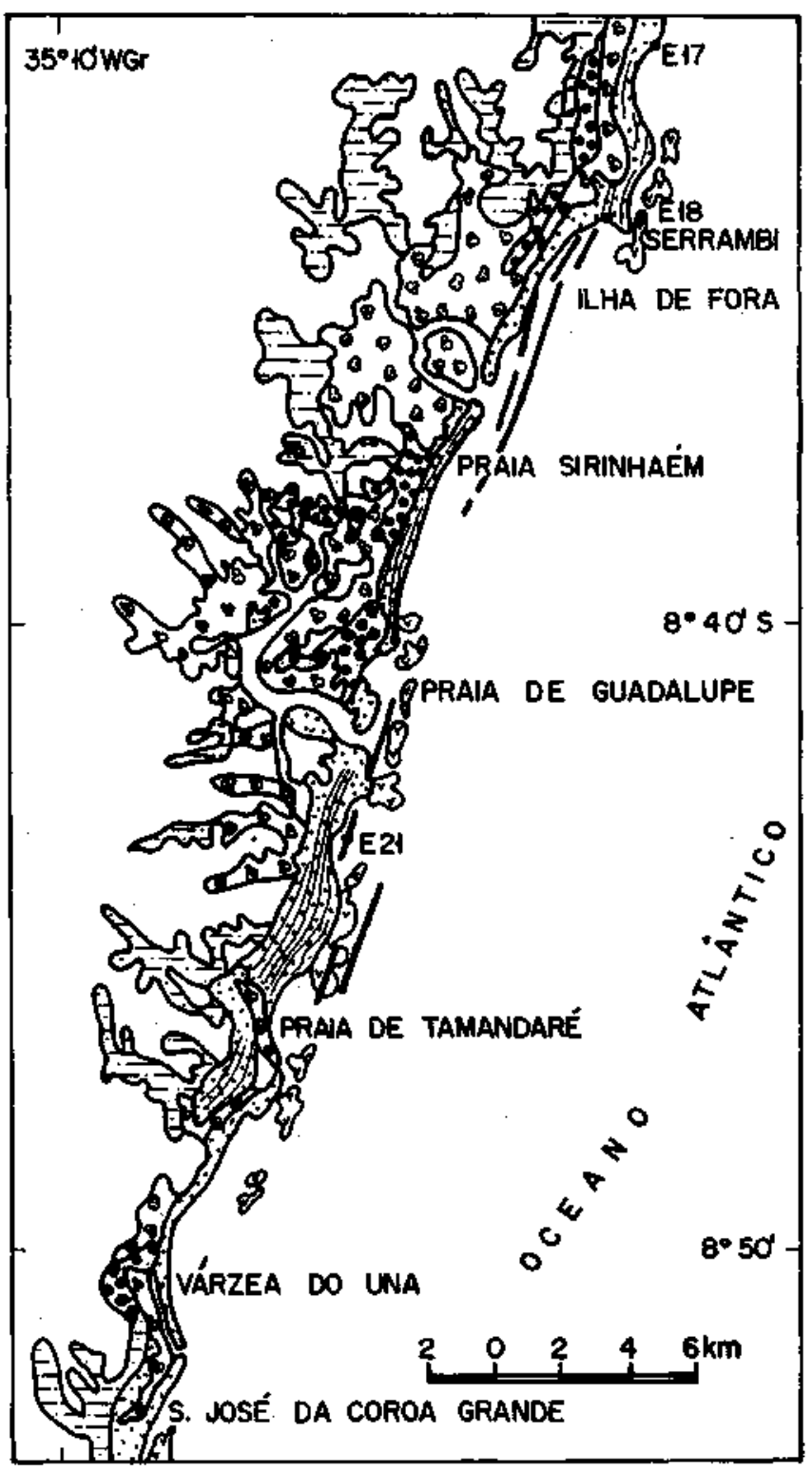

Figura 4 - Mapa Geológico do Quaternário costeiro do Estado de Pernambuco: trecho Serrambi - São José da Coroa Grande (Simbologia da Fig. 2)

Figure 4 - Geologic map of the Quaternary coastal deposits of the State of Pernambuco: sector Serrambi - São José da Coroa Grande (See Fig. 2 for legend)
Depósitos de mangue Em toda costa pernambucana são encontrados manguezais em franco desenvolvimento, que ocorrem normalmente em regiões protegidas da ação das ondas, nas margens de canais de maré e nas porções distais de vales de rios e riachos (Figs. 2, 3 e 4). Seus depósitos compreendem predominantemente materiais argilo-siltosos com muita matéria orgânica finamente dividida, restos de madeira e conchas.

Bancos de arenito Em diversos trechos do litoral do Estado de Pernambuco ocorrem bancos de arenito formando feições lineares que se estendem, às vezes, continuamente, por cerca de 10 km (Figs. 3 e 4). Esses bancos afloram na baixamar ou mesmo, alguns, ligeiramente acima do nível médio do mar e se dispõem paralelamente ao litoral por longos trechos, normalmente formando duas ou três faixas de bancos, apresentando em média 20-60 $\mathrm{m}$ de largura por 3 a $4 \mathrm{~m}$ de espessura (Mabesoone 1964). Em alguns locais, eles aparecem diretamente na face da praia. Segundo Mabesoone (1964), os bancos de arenito consistem em areias com $20 \%$ a $80 \%$ de quartzo, sendo o restante constituído de fragmentos carbonáticos, principalmente de moluscos e algas. Normalmente, apresentam estratificações cruzadas dos tipos planar e acanalada. Mabesoone (1964) refere-se ao fato de que, quanto mais próximos à praia, mais friáveis são os arenitos, sendo que alguns desses bancos, aparentemente, estão-se formando na atualidade, como aponta o referido autor o caso da praia de Bairro Novo, ao norte de Olinda.

Inicialmente, esses corpos de arenito foram reconhecidos como originários de sedimentos praiais (da face da praia) consolidados por carbonato de cálcio (Hartt 1870, Branner 1902), daí o nome de arenito de praia (beachrock). Posteriormente, Bigarella (1975), confirmando estudos anteriores de Ottman (1960) e de Mabesoone (1964), que apontavam uma origem na antepraia para essas rochas, constatou, a partir de estudos de suas estruturas sedimentares, que todos os afloramentos por ele analisados apresentavam estruturas típicas daquela região, concluindo então pela impropriedade do termo arenito de praia, no caso. Assim, propôs o termo arenito de recife (reef sandstone). No presente trabalho, por se entender que, do ponto de vista sedimentológico, a palavra recife se refere a uma construção orgânica, esses peculiares corpos rochosos são aqui denominados bancos de arenito, um termo meramente descritivo, independente de se terem originado na face da praia ou na antepraia.

Observações feitas pelos autores deste trabalho atestam que alguns bancos de arenitos presentes na costa do Estado de Pernambuco são de fato arenitos de praia típicos. Não foi tentada entretanto uma separação em mapa dos diferentes tipos genéticos de bancos de arenito tendo em vista a impossibilidade de diferenciá-los em fotos aéreas e de visitar todas as ocorrências em campo.

Por fim, há que mencionar que a construção de pelo menos alguns destes bancos de arenito deve estar ligada a níveis marinhos mais elevados que o atual, conforme já havia sugerido anteriormente Mabesoone (1964). Essa afirmativa seria verdadeira para aqueles bancos de arenito que se formaram na região de antepraia (com cruzadas acanaladas) e hoje se encontram acima do nível da maré baixa atual, nível este que delimita no perfil da zona costeira o limite entre a face da praia e a antepraia.

Adicionalmente, diversas datações atestam a correlação entre a idade dos bancos de arenito e níveis de mar mais elevados nas regiões costeiras da Bahia (Martin et ai. 1980) e Alagoas (Barbosa et al. 1986a). No Estado de Pernambuco, além de uma datação realizada por Delibrias \& Laborei (1971), que forneceu uma idade de 5.900 \pm 300 anos A.P, (LJ1367, Tab. 1), duas outras amostras coletadas pelos autores deste trabalho nas estações E-10 e E-09 (Fig. 3) forneceram, respectivamente, as idades 
Tabela 1 - Amostras datadas pelo método do carbono 14

Table 1 - Samples dated by carbon-14 method

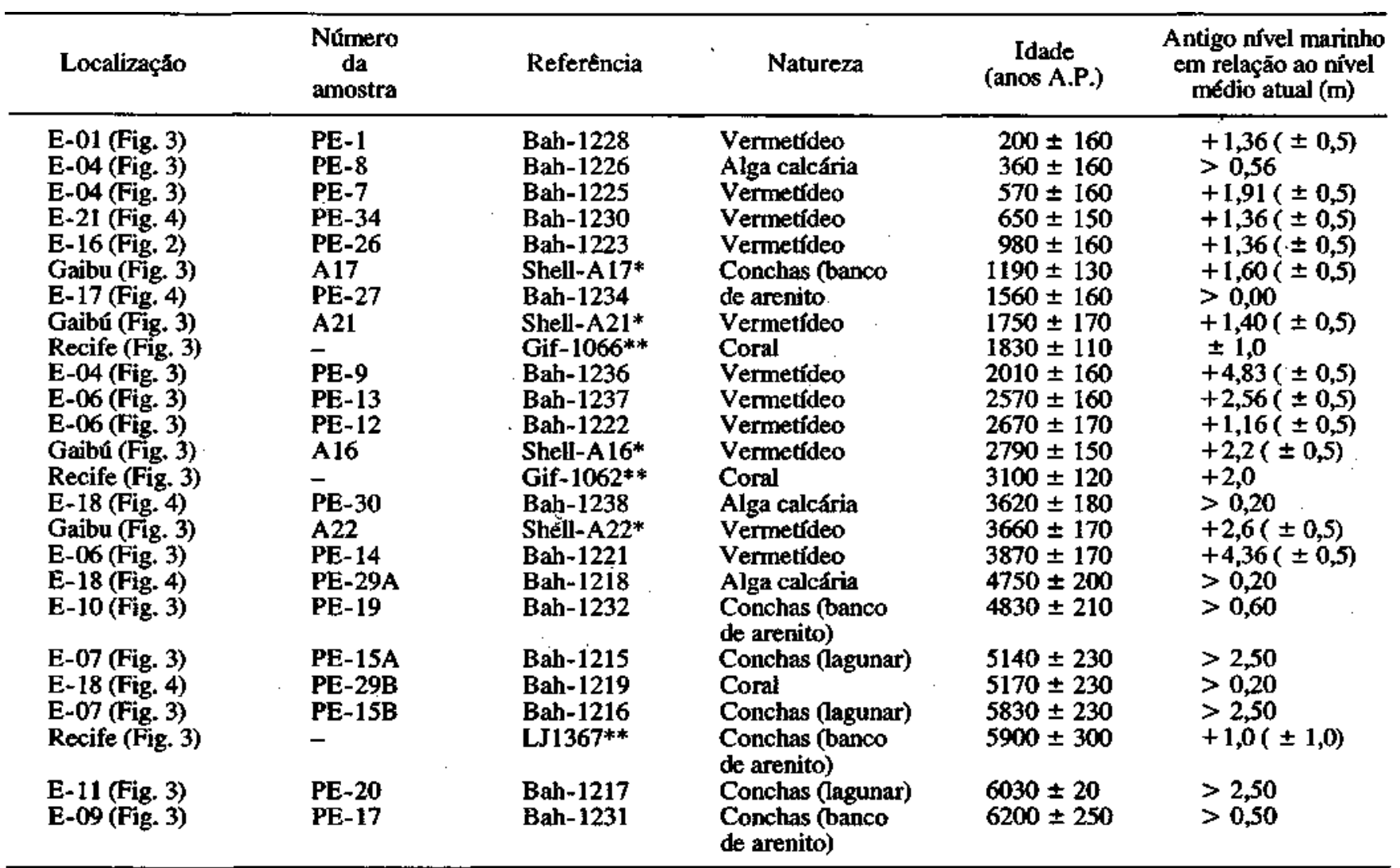

* Van Andel \& Laborel (1964)

** Delibrias \& Laborel (1971)

de $4.830 \pm 210$ e $6.200 \pm 250$ anos A.P. (Tab. 1).

RECIFES DE CORAIS As descrições dos recifes de corais na costa de Pernambuco têm como base os trabalhos de Branner (1904) e de Laborei (1969a, b) e as observações de campo feitas durante a realização do presente trabalho.

A grande maioria dos recifes de corais ao longo da costa do Estado de Pernambuco é constituída de corpos alongados e descontínuos, com o eixo maior paralelo à linha da costa. As dimensões individuais desses corpos recifais variam de menos de $1 \mathrm{~km}$ de comprimento até cerca de $4 \mathrm{~km}$, nos recifes mais próximos à praia. Já os bancos recifais submersos, localizados para fora da linha da costa, chegam a alcançar extensões de até $10 \mathrm{~km}$, como, por exemplo, os recifes em frente à ilha de Itamaracá (Fig. 2) e à praia de Boa Viagem (Fig. 3). As lagunas variam de algumas poucas dezenas de metros a cerca de 1 $\mathrm{km}$ nos recifes com formas irregulares das praias de Serrambi e Tamandaré (Fig. 4). A profundidade das águas circundantes raramente ultrapassa os $10 \mathrm{~m}$. A localicação e a morfologia geral desses corpos recifais sugerem uma estreita relação com os bancos de arenito que lhes estão associados.

Os corpos recifais localizados mais próximos à costa, a exemplo do observado na área de Abrolhos (Leão 1982, Leão et al. 1982), na Ilha de Itaparica, na Baía de Todos os Santos (Araújo 1984, Araújo et al. 1984) e no litoral norte do Estado da Bahia (Nolasco \& Leão 1986, Nolasco 1987), apresenta um topo truncado que ocorre ficar completamente emerso durante as marés baixas. Essa configuração do topo desses recifes, aplainado e irregular, formou-se em conseqüência da erosão das partes mais altas dos recifes, que cresceram acompanhando o nível do mar e foram expostas subaereamente durante a regressão marinha que sucedeu à Ultima Transgressão. (Leão et al. 1985).

Os recifes crescem com uma forma particular de colunas isoladas, com o topo expandido lateralmente como a cabeça de cogumelos (Fig. 5). Essa forma de crescimento dos recifes de corais do Brasil foi descrita pela primeira vez por Hartt (1870), que os denominou de chapeirões. Onde o crescimento desses chapeirões é muito denso, eles coalescem lateralmente por seus topos formando os corpos recifais maiores com formas e dimensões variadas. $\mathrm{Na}$ área estudada, os chapeirões isolados que alcançam o limite do nível do mar têm alturas em torno de 5 a $6 \mathrm{~m}$. Colunas menores e, algumas vezes, formadas por apenas uma única espécie de coral e com menos de 1 $\mathrm{m}$ de altura, são comuns bordejando os lados protegidos das estruturas recifais maiores (Fig. 5). A fauna coralina responsável pela construção desses corpos recifais é pobre em número de espécies. Das 18 espécies de corais descritos para os recifes brasileiros (Laborei 1969b), apenas nove estão referidas nos recifes da costa pernambucana (Laborei 1969a).

Embora não existam testemunhos da estrutura interna e do substrato dos recifes estudados, Laborei (1969a), com base em observações feitas durante mergulhos realizados na zona da frente de alguns recifes, sugere que esses recifes de corais holocênicos se instalaram e cresceram sobre bancos de arenitos submersos (Fig. 5). A morfologia dos recifes, presentes na costa de Pernambuco, é muito semelhante à dos recifes superficiais da praia de Jauá, no litoral norte do Estado da Bahia, os quais estão assentados sobre bancos de arenitos. Esses bancos apresentam idades entre 6.500 e 6.000 anos A.P. enquanto os 


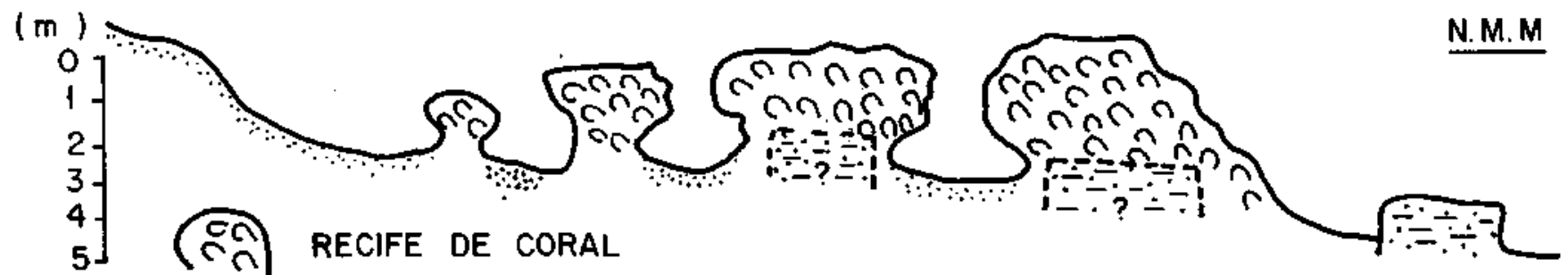
:=": BANCO DE ARENITO

Figura 5-Perfil esquemático dos recifes de coral e do banco de arenito da praia de Tamandaré (segundo LaborelJ969a) Figure 5 - Schematic profile across coral and sandstone reefs off Tamandaré beach (after Laborei 1969a)

recifes de corais são datados entre 3.800 e 2.800 anos A.P. (Nolasco \& Leão 1986, Nolasco 1987). É possível que esse cenário também seja válido para a costa de Pernambuco. Quando o nível médio do mar alcançou níveis mais elevados que o atual, os bancos de arenito já cimentados foram afogados e, sobre esse substrato consolidado, fixaram-se as larvas da espécies de corais precursores dos recifes atuais. Na costa do Estado de Alagoas, contígua, Barbosa et al. (1986a) dataram sete amostras de recifes de corais que atestam a idade holocênica dos mesmos, com idades variando entre $1.900 \pm$ 150 (Bah 1162) e $5700 \pm 230$ anos A.P. (Bah 1149). Na costa do Estado de Pernambuco, além das duas datações feitas por Delibrias \& Laborei (1971), que apresentam idades de 1830 \pm 110 (Gif 1066) e $3100 \pm 120$ anos A.P. (Gif 1062), durante a realização do presente trabalho foi datada uma amostra de coral coletada na estação E-18 (Fig. 4), que forneceu uma unidade de 5170 \pm 230 anos A.P. (Bah 1219( (Tab. 1).

\section{SIGNIFICADO DAS DATAÇÕES RADIOMÉTRICAS}

A figura 6 mostra o posicionamento no tempo e no espaço dos diferentes testemunhos de níveis marinhos elevados presentes na região costeira do Estado de Pernambuco apresentados na tabela 1. Nessa figura também aparece a curva das variações relativas do nível médio do mar durante os últimos 7.000 anos para a região de Salvador (BA), segundo Martin et al. (1980). Além das datações realizadas em corais e em conchas de moluscos coletadas nos bancos de arenito e nos depósitos lagunares, mencionados anteriormente, aparecem também na figura 6 outras 15 datações, sendo 12 realizadas em incrustações de vermetídeos e três, em algas calcárias. Dessas 15 datações, quatro são de Van Andei \& Laborei (1964) e as restantes deste trabalho (Tab. 1).

Na figura 6 aparecem dois grupos de amostras que apresentam graus de certeza distintos quanto ao posicionamento das mesmas no espaço. O primeiro grupo, representado pelas datações realizadas em corais, algas calcárias, conchas de moluscos inclusas em bancos de arenito e em sedimentos lagunares (Fig. 6 e Tab. 1), não dá informações precisas quanto ao posicionamento do nível médio do mar pretérito, fornecendo apenas uma altura mínima para o mesmo. Vale ressaltar que, nesse sentido, em relação às amostras de conchas coletadas nos sedimentos lagunares, essa altura mínima deve estar subestimada, se levado em conta o fato de esses sedimentos deverem ter sofrido compactação e dessecação, processos que, como observa Dominguez (1987), fazem reduzir a espessura original do pacote de sedimentos lagunares e, consequentemente, diminuir a amplitude das mudanças do nível do mar quando tais indicadores são usados. O segundo grupo, representado pelas datações efetuadas em vermetídeos (Fig. 6 e Tab. 1), fornece informações quanto ao posicionamento do nível pretérito do mar com uma precisão de $\pm 0,5 \mathrm{~m}$. Em alguns casos, quando as amostras são coletadas em regiões de mar batido, como as amostras PE9 e PE7 (Fig. 6 e Tab. 1), colhidas no promontório formado pelo Cabo de Santo Agostinho (Fig. 3), a zona ecológica dos vermetídeos pode ser sobrelevada de até mais de $1 \mathrm{~m}$ (Laborei 1986).

Observa-se pela figura 6 que a curva de Salvador apresenta três níveis marinhos elevados em torno de 5,3 e 2,5 m, respectivamente, há cerca de $5.200,3.500$ e 2.400 anos A.P., separados por dois níveis baixos, por volta de 4.000 e 2.700 anos A.P. De início, o que se pode constatar é não existir uma exata concordância entre o posicionamento das datações efetuadas em Pernambuco com o traçado da curva de Salvador. Todavia, observa-se que, de uma maneira geral, a partir do segundo nível elevado mostrado na curva de Salvador até o presente (Fig. 6), as datações realizadas em vermetídeos também sugerem uma tendência de abaixamento do nível do mar, bem como a existência do nível baixo em torno de 2.700 anos A.P. Em relação ao nível mais alto, por volta de 5.200 anos A.P., as datações realizadas em corais, algas calcárias e nas conchas inclusas em bancos de arenito e em sedimentos lagunares, não indicam esse nível. Esse fato, provavelmente, deve estar relacionado às limitações intrínsecas à avaliação do posicionamento desses tipos de indicadores, conforme se apontou anteriormente. Mesmo assim, vale ressaltar que as amostras lagunares, PE15A, PE15B e PE20 (Fig. 6 e Tab. 1), que apresentam idades próximas ao máximo da Última Transgressão, indicam níveis marinhos superiores a $2,5 \mathrm{~m}$, dados esses compatíveis com o modelo evolutivo definido para seqüências sedimentares semelhantes na costa brasileira (Dominguez et al. 1987).

Por fim, deve-se mencionar que o fato de as datações realizadas nas amostras de vermetídeos PE 14 e PE9 (Fig. 6 e Tab. 1) apresentarem posicionamentos bastante díspares em relação à curva de Salvador, deve estar relacionado às seguintes razões: no caso da amostra PE 14, há um provável rejuvenescimento em sua idade pelo fato de os tubos de vermetídeo estarem preenchidos por material carbonático provavelmente mais recente. É possível, portanto, que essa amostra seja indicadora de um nível marinho bem próximo ao máximo da Última Transgressão. Quanto à amostra PE9 (Fig. 6 e Tab. 1), coletada no Cabo de Santo Agostinho, a mesma já devia estar originalmente sobrelevada pelas razões citadas anteriormente.

CONCLUSÃO A região costeira do Estado de Pernambuco apresenta um esquema evolutivo quaternário que se enquadra no modelo anteriormente definido para as regiões costeiras dos Estados de Alagoas, Sergipe, Bahia, Rio de Janeiro e São Paulo. Assim, são aí encontrados testemunhos de dois grandes episódios transgressivos quaternários. O primeiro, pleistocênico, com um máximo atingido há 120.000 anos A.P., é representado por terraços marinhos com alturas de 7 a $11 \mathrm{~m}$ acima da preamar atual e, o segundo, holocênico, com um máximo há 5.000 anos A.P., apresenta um maior numero de testemunhos, na forma de: 1. terraços marinhos, que alcançam alturas de até $5 \mathrm{~m}$ acima da preamar atual; 2. depó- 


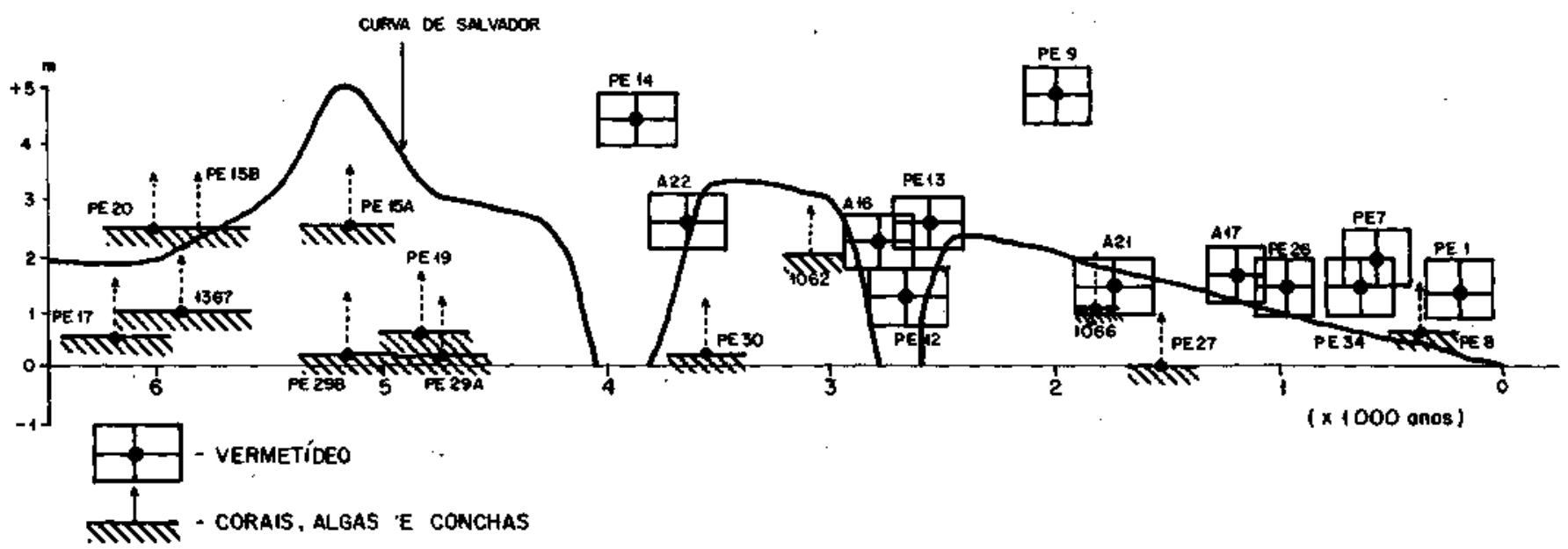

Figura 6 - Posicionamento no tempo e no espaço dos diferentes testemunhos de níveis marinhos elevados na região costeira do Estado de Pernambuco que foram datados pelo método do carbono 14

Figure 6 - Testimonies of higher than present sea levels for the coast of the State of Pernambuco positioned in time and space. All samples dated using the Carbon-14 method

sitos lagunares; 3. recifes de corais e de algas coralinas; e 4. bancos de arenito. Datações radiométrícas realizadas em 25 amostras de diferentes indicadores de níveis marinhos elevados, apesar das limitações intrínsecas de alguns indicadores relativas às informações fornecidas pelos mesmos quanto a seu posicionamento no espaço, sugerem ter havido na costa do Estado de Pernambuco, de uma maneira geral, uma gradativa descida do nível do mar, de 5.000 anos A.P. até o presente. Durante esse período, o nível do mar experimentou, prova- velmente, um abaixamento de cerca de $5 \mathrm{~m}$.

Agradecimentos Os autores querem deixar aqui expressos seus agradecimentos à Geóloga Marjorie Cseko Nolasco, que acompanhou os trabalhos de campo. Recursos para a execução desta pesquisa foram fornecidos pelo Programa de Pesquisa e Pós-Graduação em Geofísica (PPPG/UFBa) e Conselho Nacional de Desenvolvimento Científico e Tecnológico $(\mathrm{CNPq})$.

\section{REFERÊNCIAS BIBLIOGRÁFICAS}

ARAÚJO, T.M.F. 1984. Morfologia, composição, sedimeniotogia e história evolutiva do recife de coral da üha de Itaparica, Bahia. 90p. (Dissertação de Mestrado, UFBa).

ARAUUJO, T.M.F.; LEÃO, Z.M.A; LIMA, O.A.L. 1984. Evolução do recife de coral da Ilha de Itaparica determinada a partir de dados geológicos e geoffsicos. In: CONGR. BRAS. GEOL., 33, Rio de Janeiro, 1984. Anais... Rio de Janeiro, S6G. v. 1, p. 159-169.

BARBOSA, L.M.; BITTENCOURT, A.C.S.P.; DOMINGUEZ, J.M.L.; MARTIN, L. 1986a. The Quaternary coastal deposits of the State of Alagoas: Influence of the relative sealevel changes. In: RABASSA, J. ed. Quaternary of South America and Antarctic Peninsula. Balkema Pub., vol. 4, p. 269-290.

BARBOSA, L.M.; BITTENCOURT, A.C.S.P.; DOMINGUEZ, J.M.L.; MARTIN, L. 1986b. Mapa Geológico do Quaternário Costeiro do Estado de Alagoas. In: DANTAS, J.R.A. \& SOUZA, E.P. eds., Mapa Geológico do Estado de Alagoas - 1/250.000. DGM/DNPM.

BIGARELLA, JJ. 1975. Reef sandstones from northeastern Brazil (A survey on sedimentary structures). Anais da Acad. Bras. Ciênc. 47(Supl.):395-409.

BITTENCOURT, A.C.S.P.; MARTIN, L; VILAS BOAS, G.S.; FLEXOR, J.M. 1979. Quaternary marine formations of the coast of the State of Bahia (Brazil). In: SUGUIO, K.; FAIRCHILD, R.T.; MARTIN, L.; FLEXOR, J.M. eds. Proceedings of the "1978 International Symposium on Coastal Evolution in the Quaternary", São Paulo, p.232-253.

BITTENCOURT, A.C.S.P.; MARTIN, L.; DOMINGUEZ, J.M.L.; FERREIRA, Y.A. 1983a. Evolução paleogeográfica quaternária da costa de Estado de Sergipe e da costa sul do Estado de Alagoas. Rev. Bras. Geoc., 13(2):93-97.

BITTENCOURT, A.C.S.P.; MARTIN, L.; DOMINGUEZ, J.M.L; FERREIRA, Y.A. 1983b. Mapa geológico do Quaternário costeiro do Estado de Sergipe. In: BRUNI, M.A.L. \& SILVA, H.P. eds. Mapa Geológico do Estado de Sergipe - 1/250.000. DGM/DNPM.

BRANNER, J.C. 1902. Geology of the northeast coast of Brazil. Geol. Soc.Amer.Bua., 13:41-98.

BRANNER, J.C. 1904. The stone reefs of Brazil, their geological and geographical relations, with a chapter on the coral reefs. Butt. Mus. Comparative Zool., Harvard College, Cambridge, 44 (Geol. Ser. n.7): 207-275.

BLOOM, A.L.; BROECKER, W.S.; CHAPELL, J.; MESOLELLA, K J. 1974. Quaternary sea-level fluctuation on a tectonic coast: New 230-Th/234-U dates from the Huon Peninsula, New Guinea. Quaternary Research, 4:185-205.

CAÚLA, J.A.L. 1974. Carta geológica do BrasS ao MWonesimo - Folhas Natal (SB.25) e Recife (SC.25). Brasília, MME/DNPM. 41p. (Texto explicativo).

CARVALHO, R.F. \& COUTINHO, P.N. 1979. Evolução da área da Lagoa Olhos-d'agua (Recife, PE). In: SIMP. REG. GEOL., 9, Natal, 1979. Atas... Natal, SBG. p. 180-201.

CHAPELL, J. \& VEEH, H.H. 1978. Late Quaternary tectonic movements and sea-level changes at Timor and Atauro Island. Geol. Soc.Amer.Bua., 89:356-368.

DELIBRIAS, C. \& LABOREL, J. 1971. Recent variations of sea-level along the brazilian coast. Quaternária, p. 45-49.

DOMINGUEZ, J.M.L. 1987. Quaternary sea-level changes and the depositional architecture of beach-ridge strand plains along the east coast of Brazil. EUA. 288p. (PhD Dissertation, University of Miami) Flórida.

DOMINGUEZ, J.M.L.; MARTIN, L.; BITTENCOURT, A.C.S.P. 1987. Sea-level history and Quaternary evolution of river mouthassociated beach-ridge plains along the east-southeast Brazilian Coast: a summary. Soe. Econ. Paleont. Min., Special Publication, 41:115-127.

HARTT, C.F. 1870. Geology and Physical Geography of Brazil. Boston, 
Fields, Osgood and Co. $620 \mathrm{p}$

KEGEL, W. 1955. Geologia do fosfato de Pernambuco: Brasil. Rio de Janeiro, Div. Geol. Min.. 54 p. (Boi. 157).

LABOREL, J.L. 1969a. Lês peuplements de madreporaires dês cotes tropicales du Brésil. Ann. Univ. d Abidjan, serie E, II, fase $3,260 \mathrm{p}$

LABOREL, J.L. 1969b. Madreporaires et hidrocoralliaires recifaux dês cotes brésiliennes. Systematíque, ecologie, repartition verticale et geographic. Ann. Inst. Oceanogr. 47:171 -226.

LABOREL, J.L. 1986. Vermetid gastropods as sea-level indicators, In: O. VAN DE PLASSCHE ed. Sea-Level Research - A Manual for Collection and Evaluation of Data. England, GeoBooks. p. 281-310.

LEÃO, Z.M.A.N. 1982. Morphology, geology and developmental history of the southernmost coral reefs of Western Atlantic, Abrolhos Bank, Brazil. Flórida. 218p. (PhD Dissertation, University of Miami)

LEÃO, Z.M.A.N.; ARAÚJO, T.M.F.; NOLASCO, M.C. 1982. Recifes de corais do Estado da Bahia. In: SIMP. QUATERNARIO DO BRASIL, 4, Rio de Janeiro, 1982. Atas... Rio de Janeiro, CTCQ/SBG. p. 225-258.

LEÃO, ZMZN; BITTENCOURT A.C.S.P. DOMINGUEZ J.M.L.; NOLASCO, M.C.; MARTIN, L. 1985. The effects of Holocene sea level fluctuations on the morphology of the Brazilian coral reefs. RevJBras.Geoc., 15(2):154-157.

MABESOONE, J.M. 1964. Origin and age of the sandstone reefs of Pernambuco (Northeastern Brazil). Joum JSedJ>et. 34(4):715-726.

MABESOONE, J.M. 1966. Relief of Northeastern Brazil and its correlated sediments. Zeitschrift fur Geomorfologie N.F. Bd. 10. Heft 4.

MABESOONE, J.M. 1978. Panorama geomorfológico do Nordeste brasileiro. Geomorfologia, 56:16 p.

MARTIN, L.; FLEXOR, J.M.; VILAS BOAS, G.S.; BITTENCOURT, A.C.S.P.; GUIMARÃ̂S, M.M.M. 1979. Coube de variations du niveau relatif de la mer au cours des 7.000 dernieres années sur un secteur homogène du littoral bréseilien (Nord de Salvador-Bahia). In: SUGUIO, K.; FATRCHILD, T.; MARTIN, L.; FLEXOR, J.M. eds. Proceedings of the International Symposium on Coastal Evolution in the Quaternary. São Paulo, p. 264-274.
MARTIN, L.; BITTENCOURT, A.C.S.P.; VILAS BOAS, G.S.; FLEXOR, J.M. 1980. Texto expHcativo para o mapa geológico do Ouaternário costeiro do Estado da Bahia - Escala 1:250.000. CPM.SME-BA.57p.

MARTIN, L.; BITTENCOURT, A.C.S.P.; VILAS BOAS.G.S. 1982. Primeira ocorrência de corais pleistocênicos da costa brasileira Datação do máximo da Penúltima Transgressão. Rev. Ciências da Terra, 3:16-17.

MORAES, L.J. 1928. Estudos geológicos do Estado de Pernambuco. Rio de Janeiro, Serv. Geol. Min. Brasil. 57 p. (Boi. 32).

NOLASCO, M.C. \& LEÃ̃, Z.M.A.N. 1986. The carbonate buildups along the northern coast of the State of Bahia, Brazil. In: RABASSA, J., ed. Ouaternary of South America and Antarctic Peninsula. Balkema Pub. v. 4, p. 159-190.

NOLASCO, M.C. 1987. Construçôes carbonáticas da costa norte do Estado da Bahia (Salvador a Subaúma). Salvador. 143 p. (Dissertação de Mestrado/IG/UFBa).

OTTMAN, F. 1960. Une hyphotèse sur 1'origine des "arrecifes" du Nordestebresilien.Fomi.5oc. GeoLFrance, 7:175-176.

REBOUÇAS, A.C. 1965/19/66. Sedimentos da Baía de Tamandare, Pernambuco. Trab. Inst. Oceanografico, Universidade Federal de Pernambuco. 718:187-206.

SUGUIO, K. \& MARTIN, L. 1978. Quaternary marine formations of the State of São Paulo and Southern Rio de Janeiro. In: "1978 INTERNATIONAL SYMPOSIUM ON COASTAL EVOLUTION IN THE QUATERNARY". 55 p. (Sp. Publ., 1).

SUGUIO, K.; MARTIN, L.; BITTENCOURT, A.C.S.P. DOMINGUEZ, J.M.L.; FLEXOR, J.M. 1985. Flutuaç̃es do nível relativo do mar durante o Quaternário superior ao longo do litoral brasileiro e suas implicações na sedimentação costeira. Rev. Bras. Geoc., 15(4):273-286.

VAN ANDEL, T.H. \& LABOREL, J. 1964. Recent high relative sea-level stand near Recife, Brazil. Service, 145:580-581.

MANUSCRITO A599

Recebido em 17 de maio de 1989 Revisão do Autor em 16 de novembro de 1989 Revisão aceita em 16 de novembro de 1989 